\title{
AC 2009-331: USING EPLAN ROOM FOR ESTIMATING AND BIDDING CONSTRUCTION PROJECTS: A NEW TOOL IN CONSTRUCTION ENGINEERING EDUCATION DELIVERY
}

Virendra Varma, Missouri Western State University

Virendra K. Varma, Ph.D., P.E., F. ASCE, is Professor and Chairman of the Department of Engineering Technology at Missouri Western State University. 


\title{
ePlan Room for \\ Estimating and Bidding Construction Projects: A New Tool in Construction Engineering Education Delivery
}

\begin{abstract}
Integration of Information Technology (IT) in construction contracting and project delivery has recently resulted in fundamental changes in how contractors can estimate and bid on construction projects. With the introduction of Electronic Plan Room (ePlan Room), construction estimating and bidding projects has become a lot quicker and simpler. Due to the availability of 24-Hour Internet access, contractors can review several projects in a short time, and bid on the jobs that they are serious about. On-Screen take-offs can be done using an easy-to-use system, and contractors can optimize their efforts by saving on travel and labor costs thus resulting in more successful construction project bids. This paper describes the basic and advanced features of Missouri's AGC ePLAN Room, and highlights the advantages of integration of AGC-Missouri's and similar ePLAN rooms in construction engineering/management curriculums in the overall delivery of construction engineering-related education. The paper is directed to the educational and research interests of the community of students and faculty belonging to the disciplines of civil/construction and architectural engineering, construction science and construction management. The exposure of students to the database of several construction projects in a relatively short time allows them to view plans and specifications on-line, and do the quantity take-offs on-screen. Full sets of plans and specifications can be printed in office or a construction trailer. Author's recommendations on the adoption and use of Missouri's AGC ePLAN Room and similar ePlan Rooms is discussed in the context of other recent advancements in the construction engineering and management education.
\end{abstract}

\section{Introduction}

Information Technology (IT) has become an indispensable and integral part of the construction practice. With the availability of 24-Hour Internet access, fundamental changes from construction estimating and bidding to management of construction documents in a virtual environment are already under way. Contractors of all sizes, from small to mid-size, to large companies, have begun to understand how subscribing to, and utilizing ePlan rooms (the Electronic Plan Room) can boost their productivity in estimating and bidding. With the aid of On-Screen take-offs, the contractors can reduce travel and labor costs. This paper discusses the basic features of AGC-Missouri's ePlan Room (there are other ePlan Rooms), and highlights the advantages, in general, of using ePlan rooms in construction engineering and management curriculums. The exposure of students to the database of construction projects in an ePlan room allows them to view plans and specifications on-line, and do the quantity take-offs on-screen. In the light of ePlan rooms, other recent developments in construction practice, are also discussed in the paper to emphasize integrated project delivery that insures sharing and providing information to the entire construction team. 


\section{What is an ePlan Room?}

An ePlan room is an electronic on-line plan room with access to the same and many more features that a physical plan room offers. For example, ePlan, the AGC of Missouri's on-line plan room provides the following features to its subscribers:

- The ePlan is an On-line Service, therefore there is a subscription fee.

- It gives information on hundreds of bid projects. The information includes plans, specifications, addenda, etc.

- It gives instant downloading of any document with keyword search capability.

- It allows On-Screen Take-Offs.

- It lessens the time searching for bid projects, hence bolsters profits.

\section{Other Features of ePlan Room:}

Some of the additional services of the AGC of Missouri's ePlan are ${ }^{1}$ :

- You can track subs and suppliers who are bidding on the job.

- You can manage contacts by the CSI code.

- Through an ePlan portal service as a part of subscription service, you can manage unlimited number of projects at one time.

You can have redundant storage of your files without additional infrastructure investment.

You can create mark-ups digitally.

- It has an electronic closeout feature.

ePlan rooms can be used by contractors, subcontractors, fabricators, suppliers, etc. A steel fabricator may use the electronic plan room for bidding and estimating in the same way as does a general contractor but his/her needs may be different; however, there are commonalities in the use of the ePlan room. The author acknowledges the efforts of Ron E. Edwards, CSI, Director of Business Development, ePlan Online Plan Room, AGC of Missouri, Construction News, Inc., who has introduced the free AGC-Missouri ePlan University training program to train estimators and suppliers on their new online plan room right from one's own desktop. The author participated in the program along with his students and found the program highly user-friendly.

\section{A Structural Steel Fabricator's Use of An ePlan Online Plan Room:}

In response to a telephone survey conducted by the author, one company that has fabricated structural steel for hospitals, sports stadiums, schools, colleges, universities, and industrial structures, the use of the electronic plan room was spelled out as follows:

"We use the ePlan rooms to know what is bidding, when it is bidding, and who it bids to. We download the design drawings and specifications direct from these sites. We are then sent updates when addendums are added so we can include everything in the bid."

"We use our own system for estimating that is tied into our production software. It was developed for the fabrication industry and is called Fabtrol. We run a copy of the drawings from the download and input each individual steel item into the system. It then gives us our material 
and labor costs. We then add it to an Excel spreadsheet that we developed from an old hand form to figure the job totals including buy outs and erection.",2

Above is an example of a highly progressive steel fabrication plant. However, at plants that are not keeping up with the advances in computer technology and/or advancements in the information technology such as ePlan rooms, the technicians may still use the old type of forms and run the numbers on a calculator. At an unsophisticated plant, the technician may still do the hand take-off and have a clerk input for material and labor. The advantages of progressive plants are obvious --- The time to prepare an estimate can be cut by at least half, and it is more accurate compared to industry standards. Also, once the job is completed, one can make a comparison of actual job cost vs. estimate.

\section{Sample of an ePlan Estimate}

(Various broad categories and numbers are included in the form below for information only)

Estimate No.: 1

Date: $\quad$ 2/6/2009

Estimator: A. Bcde

Project: $\quad \mathrm{XYZ}$

Contractor: DEF

\begin{tabular}{|l|l|l|l|l|l|}
\hline $\begin{array}{l}\text { Shop } \\
\text { Fabricated }\end{array}$ & Vendor & Quantity & Unit & Extension & Total \\
\hline Material & 150 tons & 1 & Lbs & $\$ 225,000.00$ & $\$ 225,000.00$ \\
\hline Labor & $15 \mathrm{MH}$ ton & 1750 & Hour & $\$ 60$ & $\$ 100,000.00$ \\
\hline Detailing & $25 \%$ Shop & & & & \\
\hline Engineering & & & & & \\
\hline Clean Up & & & & & \\
\hline Mark-Up & & & & $5 \%$ & \\
\hline Sub-Total & & & & & \\
\hline
\end{tabular}

\begin{tabular}{|l|l|l|l|l|l|}
\hline Brought Out & Vendor & Quantity & Unit & Extension & Total \\
\hline Joists \& Deck & JKL & 1 & Lot & $\$ 80,000.45$ & $\$ 80,000.45$ \\
\hline & & & & & \\
\hline & & & & & \\
\hline Bond & $\$ 5 / 1000$ & & & & \\
\hline Cost & & & & $5 \%$ & \\
\hline Mark-Up & & & & & \\
\hline Sub-Total & & & & & \\
\hline
\end{tabular}

\begin{tabular}{|l|l|l|l|l|l|}
\hline Selling Price & Vendor & Quantity & Unit & Extension & Total \\
\hline Total & & & & & \\
\hline Sales Tax & & & & & \\
\hline Erection & ST & 1 & Lot & $\$ 200,000.00$ & $\$ 200,000.00$ \\
\hline Mark Up & & & & & \\
\hline
\end{tabular}


The estimator can sum up the contract amounts in categories such as follows:

Shop Fabrication

Buy Outs

Erection

Detailing

Tax

Total Quote: $\quad \$ \$ \$ \$$

Note: Full extended Bill of Materials should be produced in a spreadsheet format that takes into account shop hours, and field hours to come up with an accurate estimate. Freight must also be included.

\section{Integrating ePlan Rooms in Construction Engineering and Management Education}

Today's AEC (Architecture/Engineering/Construction) industry cannot function without the integration of information technology. And nor can today's delivery of construction engineering-related education be complete without the exposure of students to ePlan room capabilities and benefits.

ePlan is AGC of Missouri product. There are other ePlan room online services such as McGraw Hill's. Besides estimating and bidding, the electronic plan room services include management of construction documents from pre-construction to close-out. The effectiveness of online bid solicitations and management of construction documents in a virtual environment can be best described by the user alone... it is user-friendly and highly profitable.

Some of the main electronic plan room services are:

- McGraw Hill Construction (Dodge)

- iSQFT

- CM Reed (Reed Construction Data)

Electronic plan rooms provide information on construction projects, including document viewing of plans and specifications. As indicated above, steel fabricators are also utilizing electronic plan room services. Steel fabricators can work as subcontractors or suppliers on a project. Other trades can participate in the ePlan services via subscription as well.

\section{Faculty Need to Plan to Integrate ePlan in Instruction}

The author after attending an internet-based AGC-Missouri's ePlan University presentation on the online plan room, invited the presenter to give a seminar and a demonstration to the students. The presenter was given the guest account to login to the university system to deliver his presentation. He highlighted the following points in his presentation: ${ }^{3}$ 
1. Students as future construction professionals will have access to hundreds of Missouri projects

2. They will be able to view all project documents.

3. They will be able to do free downloads and prints.

4. They will be able to track projects. (ITB feature w/RSVP Tracking)

5. They will receive daily notifications via email.

6. They will have the ease of Keyword Search on all Specs.

7. They will be able to do On Screen Takeoff Integration.

8. Plus they will be able to do management of construction documents.

The AGC of Missouri is doing its best to train contractors and subcontractors on their ePlan room. Once they have attended the initial ePlan University webinar, they are invited to have a free two-week training session. For the author, the next step is to have his students participate in the two-week training session in Fall 2009 so that they can do the actual on-screen quantity takeoffs. This will serve as a supplement to a regular course in construction estimating utilizing the Timberline software.

\section{Advantages of ePlan Online Room and Other Advancements in Construction Practice}

As we have all experienced in all facets of life and work, working online is fast and efficient just as ordering goods online is quick and productive. We are moving very rapidly toward a paperless world and are utilizing project information management (PIM) software to increase productivity and complete projects on time and within budget. If information can be transmitted to construction professionals digitally and accurately in a transparent manner, the likelihood of less project mistakes and greater productivity are obvious. With the dawn of BIM (Building Information Modeling) technology, the integrated practice of coordination and documentation of design and construction of building structures can only go one step further with the addition of the ePlan room initiatives for estimating and bidding. Learning ePlan online is fast and easy. And our students and faculty are ready to adopt it in their curriculum.

\section{Conclusion}

The electronic plan room, as a tool in the delivery of construction engineering education, has arrived. It stands square on the development of computer and information technology. The integration of information technology for facilitating online estimating and bidding, and managing construction documents in a virtual environment, will enhance productivity and improve the construction practices. Students and faculty are receptive to the use of ePlan rooms in construction education; however, they need to use this tool as a supplement and not supplant other tools in the overall delivery of construction engineering education.

\section{Bibliography}

1. AGC of Missouri ePlan University, Jefferson City, MO

2. Author's Engineering Survey of Structural Steel Fabricators, Fall 2008

3. Correspondence with the AGC-Missouri Construction News, Inc., Jefferson City, MO 